\title{
Are environmentally friendly fireworks really "green" for air quality: a study from the 2019 National Day fireworks display in Shenzhen
}

\author{
Shidong Fan ${ }^{\dagger, *}$, Ying Li ${ }^{*, \dagger, *}$, Chanfang Liu ${ }^{\S}$ \\ $\dagger$ Department of Ocean Science and Engineering, Southern University of Science and \\ Technology, Shenzhen, China. \\ $\$$ Center for the Oceanic and Atmospheric Science at SUSTech (COAST), Southern \\ University of Science and Technology, Shenzhen, China. \\ $\S$ Environmental Monitoring Center, Shenzhen, China \\ ${ }^{*}$ Corresponding authors. E-mail address: liy66@,sustech.edu.cn.
}

Supporting Information is 19 pages including 5 figures and 5 tables. 


\section{S1. Details about the estimation of emissions.}

\section{S1.1 Estimation of total charge mass of one single firework in type I fireworks. We}

estimated the total charge (sum of three kinds of charges) of one single firework based on Chinese Standard GB19593-2015: Fireworks-Batteries and combinations. There are many subtypes of type I fireworks, all of which are classified into four categories, $\mathrm{A}, \mathrm{B}, \mathrm{C}$, and D, according to their different "maximum allowed charge (MAC)" (GB19593-2015). Categories A and B are for professional displays, while C and D are for individual usage, and therefore, we assume that the type I fireworks actually used in the display are all in categories A and B. Then, the total charge amount of each firework in type I is estimated as $0.045 \mathrm{~kg}$ by using $90 \%$ times those MAC (column 6 in Table 1) in GB19593-2015, since the fireworks manufacturers usually reserve some room and we estimate an average reservation of $10 \%$ for MAC.

\section{S1.2 Estimation of mass ratio of pyrotechnic charge over total charge in type II}

fireworks. We assume this mass ratio, $w$, is a constant for different subtypes since different subtypes of type II fireworks differ only in size. The charge of a single firework is also assumed to be $90 \%$ of the MAC (Chinese Standard GB19594-2015: Fireworks-Display shell), but unlike type I fireworks, there are several such values instead of one because every subtype has one (column 6 in Table 1). Then the pyrotechnic charge of a single firework is $90 \% \times \mathrm{MAC} \times w$, where $\mathrm{MAC}$ is different for each subtype. Then the total number of type II fireworks should be 


$$
\sum_{\text {subtype }} \frac{m_{p y_{-} t o t}}{90 \% \times M A C \times w}
$$

where $m_{p y_{-} t o t}$ is the total mass of pyrotechnic charge of one subtype, which is known (column 7 in Table 1). This value is $6820 / w$, which should equal to 13230; therefore, we can calculate $w$, which equals to $51.5 \%$.

\section{S1.3 Calculation of the ratio of $\mathrm{S}$ released in the form of $\mathrm{SO}_{2}$ over in the form of}

sulfate. It is obvious that $\mathrm{S}$ in ambient PM is only in the form of sulfate since PM contains no gases. Besides, $\mathrm{K}$ is a metal element that cannot turn into gas, which means $\mathrm{K}$ is conserved in black powder and in ambient PM. Therefore, the change of K:S results from the change of how much $\mathrm{S}$ content is in the solid phase. The worldwide $\mathrm{K}: \mathrm{S}$ in the black powder is quite similar $(2.75)^{1}$, and if we can roughly estimate the ratio of emitted $\mathrm{SO}_{2}$ and sulfate by using $\mathrm{K}: \mathrm{S}$ in the ambient PM. (5.73 measured by Croteau et al. ${ }^{2}$, the ratio of $\mathrm{S}$ released in the form of $\mathrm{SO}_{2}$ over in the form of sulfate $\left(\mathrm{SO}_{2} / \mathrm{sulfate}\right)$ follows eq. S2.

$$
\left(\frac{1}{2.75}-\frac{1}{5.73}\right) / \frac{1}{5.73} \approx 1
$$

\section{S2. The algorithms of dispersion in CMAQ.}

CMAQ adopts piecewise parabolic method (PPM) with a steepening procedure to calculate advection, and $K$ theory and asymmetric convective method (ACM2) to model diffusion processes. The details can be found in references, ${ }^{3-5}$ and here we present a brief description. PPM algorithm describes the concentration distribution in a grid as s 
parabola, and uses neighboring concentrations to calculate the average concentration of the grid itself. This method is somewhat more diffusive than commonly used Bott scheme, but the steepening procedure can keep the profile narrow. ${ }^{4} K$ theory deals with only turbulent diffusion, assuming turbulent diffusion are described by only eddy diffusion which is entirely similar to molecular diffusion. ${ }^{6}$ Then the most important thing in quantifying its contribution to dispersion is to parameterize the eddy diffusivities. Vertical eddy diffusivity $K_{z z}$ is parameterized with a planetary boundary layer (PBL) similarity theory, and in different stability regimes $K_{z z}$ has different formulations. Horizontal eddy diffusivity $K_{x x}$ (and $K_{y y}$ ) is parameterized with the deformation in the gridded wind field. $K_{x x}$ and $K_{y y}$ are the same in CMAQ, while in a Lagrangian model the longitudinal and transverse diffusivities may be different. ${ }^{4} K$ theory assumes eddies in sub-grid scale, which may fail when vertical eddies are large in the presence of convective conditions. Therefore, CMAQ implements ACM2, a nonlocal closure model, for convective vertical diffusion. ${ }^{7}$

\section{S3. Validation of the general performance of the modeling system.}

Simulated wind direction, wind speed, temperature, and $\mathrm{PM}_{2.5}$ are compared with observations. The meteorological observation data are those used in the observation nudging, but only 459 stations in D4 of CMAQ that have continuous hourly observations are chosen. The $\mathrm{PM}_{2.5}$ observation data are those measured at the $75 \mathrm{PM}_{2.5}$ monitoring stations. The statistical metrics, including the root mean square error 
(RMSE), mean bias (MB), mean error (ME), normalized mean bias (NMB), normalized mean error (NME), correlation coefficient $r$, and index of agreement (IOA), are shown in Table S1. The formula of these metrics along with benchmarks for some of these metrics can be found in Emery et al. ${ }^{8,9}$ It is noteworthy that for WD, the difference between observed and simulated values needs to be on the interval $[-180,180]$, and those metrics whose formula contains this difference need to be modified accordingly. ${ }^{10}$

Table S1. Model performance metrics for meteorological factors and $\mathrm{PM}_{2.5}$ from 20 to 30 September 2019.

\begin{tabular}{|c|c|c|c|c|c|c|c|}
\hline & RMSE & $\mathrm{MB}$ & $\mathrm{ME}$ & NMB & NME & $r$ & IOA \\
\hline $\mathrm{WD}\left({ }^{\circ}\right)$ & 70.87 & $0.37(\leq \pm 10)$ & $54.41(\leq 30)$ & 0.00 & 0.32 & 0.17 & 0.92 \\
\hline WS $(\mathrm{m} / \mathrm{s})$ & $1.64(\leq 2)$ & $\mathbf{0 . 6 2}(\leq \pm 0.5)$ & 1.26 & 0.36 & 0.69 & 0.39 & $\mathbf{0 . 5 9}(\geq 0.6)$ \\
\hline $\mathrm{T}\left({ }^{\circ} \mathrm{C}\right)$ & 1.76 & $0.42(\leq \pm 0.5)$ & $1.36(\leq 2)$ & 0.01 & 0.05 & 0.87 & $0.89(\geq 0.8)$ \\
\hline $\mathrm{PM}_{2.5}\left(\mu \mathrm{g} / \mathrm{m}^{3}\right)$ & 21.34 & -4.30 & 15.98 & $-0.10(< \pm 0.3)$ & $0.41(< \pm 0.5)$ & $0.56(>0.4)$ & 0.69 \\
\hline
\end{tabular}

Note. All values are calculated separately for each observation station and then averaged over all stations. The values in brackets are benchmarks taken from Emery et al. ${ }^{8,9}$ and the benchmark for $\mathrm{PM}_{2.5}$ is for 24-hour $\mathrm{PM}_{2.5}$. The values do not meet the benchmarks are denoted in bold.

\section{S4. Uncertainty analysis.}

The estimation of fireworks' emissions consists of two steps, first estimating the total charges and second estimating emission factors. The known value is the mass of pyrotechnic charge. We estimated the masses of unpacking and propellant charge by estimating the mass of total charge. In the following analysis, we use the other available 
references of mass ratio between the three charges to evaluate the uncertainties. For emission factors, similar approaches are taken. The results are listed in Table S2.

S4.1 Uncertainties in the estimation of type I fireworks charges. For type I fireworks (batteries and combinations), our estimated ratio of pyrotechnic : unpacking : propellant charge is about $1: 1: 1$, as shown in the main text section 2.2 . Here we collect available ratios from other sources to estimate the uncertainty. These ratios are only for category $\mathrm{C}$ or D fireworks (for individual usages). We assume these ratios are similar between category $\mathrm{A} / \mathrm{B}$ (for professional usages) and C/D fireworks because roughly speaking, category A/B fireworks are only larger than category C/D fireworks. The collected ratios are not given directly by the references but calculated based on the references: $12: 4: 4$ to $12: 6: 6$ for multiple-tube shells (see 2-2 in the reference by American Fireworks Standards Laboratory (AFSL) ${ }^{11}$ ), $12: 4: 8$ to $12: 12: 24$ for single-tube shells (see $2-3$ in the reference by $(\mathrm{AFSL})^{11}$ ), and about $12: 6: 6$ to $12: 9: 9$ for a colorful fireworks (we treat other minor charges than these three main charges in that fireworks as unpacking and propellant charge). ${ }^{12}$ Then the lower and upper bound of the ratios are about $12: 4: 4$ and $12: 12: 24$, respectively. Therefore, the used one, 1 : $1: 1$, could overestimate unpacking charge by $0 \%$ to $200 \%$, while overestimate propellant charge $-50 \%$ to $200 \%$.

S4.2 Uncertainties in the estimation of type II fireworks charges. For type II fireworks (aerial shells), taking a 3-inch aerial shell as an example, the estimated unpacking and propellant charge are both about $40 \mathrm{~g}$ in a single firework, as shown in the main text. From experiments of a research group, we know that a typical 3-inch 
aerial shell may contain $30 \mathrm{~g}$ black powder as unpacking charge, ${ }^{13,14}$ and $40 \mathrm{~g}$ black powder as propellant charge. ${ }^{15}$ Unpacking and propellant charges with different ingredients have different densities and different masses, but if we simply use black powder as an example, we can see that our estimation of unpacking charge and propellant charge of type II fireworks overestimated by about $33 \%$ and $0 \%$, respectively. However, the pyrotechnic charge in the references ${ }^{13,14}$ is about $40 \mathrm{~g}$ for a 3 -inch aerial shell, which means the estimated unpacking charge and propellant charge are underestimated by about $33 \%$ and $50 \%$, respectively, if we use the ratio of pyrotechnic : unpacking charge and pyrotechnic : propellant charge to estimate these two charge (4 : 3 and $4: 4$ in the references while $4: 2$ and $4: 2$ in our estimation).

S4.3 Uncertainties in the estimation of emission factors. In terms of emission factors, the difficulty is larger since all relevant data are indirect. Different charges, among the three main charges in a typical firework, have different functions and compositions, and therefore different emission factors. For unpacking and propellant charge, which are much easier to be environmentally friendly than pyrotechnic charge and have been significantly improved by the manufacturers, we assume they are close to its limit in being environmentally friendly. This assumption is based on two considerations: one is that the fireworks display attracted much attention and was concerned strongly by environmental regulators, and the other is that we want to explore the limitation of the ability of fireworks being environmentally friendly. At present, the charge with lowest smoke emission probably consists of retired military single base charge, which is almost really smokeless (see figure 6 in reference ${ }^{16}$ ) and therefore we assume its emission 
factor of PM is 5\%. Other environmentally friendly charges may emit more PM, with emission factor of PM (qualitatively) about $0.3-0.5$ of that for black powder ${ }^{17-20}$ (which means a emission factor of $21-35 \%$ if we take the emission factor for black powder as $70 \%$, as the traditional unpacking charge in Han et al. ${ }^{21}$, or $27-45 \%$ if we take the emission factor for black powder as $90 \%$, as we used for pyrotechnic charge considering the effect of heavy metals). The used value in this study, $5 \%$, is less than these values by $76-89 \%$.

For pyrotechnic charge, which contains a large amount of metal elements for shining different colors and these metals cannot be emitted in the form of gas, the emission factor is estimated based on the measured emission factor for traditional unpacking charge $^{21}$ and the fact that metal-containing pyrotechnic charge usually has higher a emission factor than black powder. ${ }^{22}$ Our estimated emission factor of $\mathrm{PM}_{2.5}$ is $45 \%$, a very high value but not far from the measured value for traditional unpacking charge $(\sim 35 \%)$. If we stick to the emission factor from combustion of traditional unpacking charge ( $\sim 35 \%)$, our estimated emission factor overestimates by $\sim 30 \%$.

Table S2. Uncertainties result from the emission estimation.

\begin{tabular}{|c|c|c|c|c|c|c|c|c|}
\hline & $m_{u n_{-} 1}$ & $m_{p r_{-} 1}$ & $m_{u n \_2}$ & $\boldsymbol{m}_{p r_{-} 2}$ & $e f_{p y}$ & $e f_{u n}$ & $e f_{p r}$ & Simulated PM2.5 \\
\hline Uncertainty & $0-200 \%$ & $-50-200 \%$ & $-33-33 \%$ & $-50-0 \%$ & $0-30 \%$ & $-89-0 \%$ & $-89-0 \%$ & $-48-32 \%$ \\
\hline
\end{tabular}

Note. $m$ : mass. ef: emission factor. un: unpacking charge. py: pyrotechnic charge. pr: propellant charge. 1 : type I fireworks. 2: type II fireworks. 
S4.4 Emission inducing uncertainties in the simulated PM2.5. The emission of PM from environmentally friendly fireworks can be calculated based on eq. S3:

$$
e^{e m i s_{P M_{-} E F}}=m_{p y} \times \frac{0.9}{1+x_{5}}+\left(\frac{m_{u n_{-} 1}}{1+x_{1}}+\frac{m_{p r_{-} 1}}{1+x_{2}}+\frac{m_{u n_{-} 2}}{1+x_{3}}+\frac{m_{p r_{-} 2}}{1+x_{4}}\right) \times \frac{0.05}{1+x_{6}}
$$

where $m_{p y}, m_{u n_{-} 1}, m_{u n_{-} 2}, m_{p r_{-} 1}$, and $m_{p r_{-} 2}$ are the originally known or estimated masses of pyrotechnic $(6520 \mathrm{~kg})$, type I unpacking $(2301.5 \mathrm{~kg})$, type II unpacking (2090.5 kg), type I propellant $(2301.5 \mathrm{~kg})$, and type II propellant charge $(2090.5 \mathrm{~kg})$. $x_{1}$ to $x_{6}$ are uncertainties listed in Table $\mathrm{S} 2$, from the left to the right. If both the masses of charges and emission factors are underestimated (the lower bounds of uncertainties in Table S2), the emission of PM would be underestimated to the largest extent. In this case, the emission of PM should be $12260.5 \mathrm{~kg}$. Then the ambient $\mathrm{PM}_{2.5}$ concentration at the five response stations would be $1.94(12260.5 / 6307.2)$ times of that in CaseEF because the response of ambient $\mathrm{PM}_{2.5}$ to emission is entirely linear (corresponding to an uncertainty in Table S2 1/1.94-1=-0.48=-48\%). Similarly, we can calculate the simulated ambient $\mathrm{PM}_{2.5}$ that was overestimated to the largest extent, which would be $0.76(4773.7 / 6307.2)$ of that in CaseEF (corresponding to an uncertainty in Table S2 1/0.76-1=0.32=32\%).

To find out the determining parameters for the emission estimation, the response of the total emission amount to the parameters (four charges and two emission factors in the eq. S3) is further estimated by fixing 5 of the 6 values and change the rest one according to the uncertainty bounds listed in Table S2. The results show that the total amount of fireworks emission is always dominated by the emission from pyrotechnic charge, $m_{p y} \times \frac{0.9}{1+x_{5}}$. Changing $x_{5}$ from 0 to $30 \%$ (by considering the emission factor between 
$0.7-0.9), m_{p y} \times \frac{0.9}{1+x_{5}}$ will change from $5868 \mathrm{~kg}$ to $4514 \mathrm{~kg}$, which account for $93 \%$ and $91 \%$ of emis $S_{P M_{-} E F}$ when we fix $x_{1}, x_{2}, x_{3}, x_{4}$ and $x_{6}$ as those in CaseEF, respectively. (If we fix $x_{1}, x_{2}, x_{3}, x_{4}$ and $x_{6}$ as that in the "Central" case, $m_{p y} \times \frac{0.9}{1+x_{5}}$ will still account for $77-72 \%$ of $\left.e m i s_{P M_{-} E F}.\right)$. This determination of the pyrothechic charge partly explains why we can well simulate the size, peaks and trackjectory of the fireworks, because the amount of this pyrotechnic charges is the provided data by the government in the real case (i.e. CaseEF).

S4.5 Uncertainties in the benefits of environmentally friendly fireworks. These uncertainties also have influence on the benefits of environmentally friendly fireworks compared to traditional fireworks. The benefit is the relative reduction of PM emission from environmentally friendly fireworks compared to that from traditional fireworks, which can be calculated by eq. S4:

$$
\text { reduction }=\left|\frac{\text { emis }_{P M_{-} E F}-e m i S_{P M_{-} T R A D}}{e m i S_{P M_{-} T R A D}}\right|
$$

where emis $_{P M_{-} E F}$ is the emission of PM from environmentally friendly fireworks (eq. S3), and emis $_{P M_{-} T R A D}$ is the emission of PM from traditional fireworks, which can be calculated as follows:

$$
\text { emis }_{P M_{-} T R A D}=\left(m_{p y}+\frac{m_{u n_{-} 1}}{1+x_{1}}+\frac{m_{p r_{-} 1}}{1+x_{2}}+\frac{m_{u n_{-} 2}}{1+x_{3}}+\frac{m_{p r_{-} 2}}{1+x_{4}}\right) \times \frac{0.9}{1+x_{5}}
$$

With any fixed mass, since there are six independent variables $\left(x_{1}\right.$ to $\left.x_{6}\right)$ each of which can take minimum and maximum values (for simplicity, we do not consider values that are not bounds in Table S2), there are 64 combinations that can produce different reductions. Among these 64 combinations, the largest reduction is $65 \%$ (it is the case 
$e f_{E F}$ uses upper bound while other parameters use the lower bounds), and the lowest reduction is $15 \%$ ( $e f_{E F}$ uses lower bound while other parameters use the upper bounds). However, not all the 64 combinations are plausible if we considered the constrain from the observations. To achieve the same simulation of $\mathrm{PM}_{2.5}$ which is constraint by the observations, the emission of $\mathrm{PM}_{2.5}$ should keep same as the value in CaseEF, which means that eq. S3 is conserved for different values of $x_{1}$ to $x_{6}$.

To roughly estimate a "central" value of the benefit, the central values (i.e. $x_{1}=100 \%$, $x_{2}=75 \%, x_{3}=0 \%$, and $\left.x_{4}=-25 \%\right)$ of masses uncertainties of unpacking and propellant charges are adopted basing on the experimentally measured emission factor (70\%) for traditional charge by $\mathrm{Han}$ et $a .^{24}$. Then, the emission factor of environmentally friendly charges $\left(e f_{E F}\right)$ can be calculated as the eq. S3 is conserved when considering the observation constraint:

$$
\begin{gathered}
m_{p y} \times 0.9+\left(m_{u n_{-} 1}+m_{p r_{-} 1}+m_{u n_{\_} 2}+m_{p r_{-} 2}\right) \times 0.05 \\
=m_{p y} \times 0.7+\left(\frac{m_{u n_{-} 1}}{1+1}+\frac{m_{p r_{-} 1}}{1+0.75}+\frac{m_{u n_{-} 2}}{1+0}+\frac{m_{p r_{-} 2}}{1-0.25}\right) \times e f_{E F}
\end{gathered}
$$

where $m_{p y}, m_{u n_{-} 1}, m_{u n_{-} 2}, m_{p r_{-} 1}$, and $m_{p r_{-} 2}$ are the mass of charges, see S4.4. It is easily calculated that $e f_{E F}=0.24$, which is almost the median between 0.05 and 0.45 . Then the benefit of using environmentally friendly fireworks is to reduce ambient $\mathrm{PM}_{2.5}$ by

$$
\text { reduction }=\left|\frac{\left(\frac{m_{u n_{-} 1}}{1+1}+\frac{m_{p r_{-} 1}}{1+0.75}+\frac{m_{u n_{-} 2}}{1+0}+\frac{m_{p r_{-} 2}}{1-0.25}\right) \times\left(e f_{E F}-e f_{\text {trad }}\right)}{\left(m_{p y}+\frac{m_{u n_{-} 1}}{1+1}+\frac{m_{p r_{-} 1}}{1+0.75}+\frac{m_{u n_{-} 2}}{1+0}+\frac{m_{p r_{-} 2}}{1-0.25}\right) \times e f_{\text {trad }}}\right|=0.35
$$

\section{S4.6 Response of the emission reduction to the uncertainties of the estimated}

parameters. The six estimated parameters have different impact on the emission reduction because reduction is a non-linear combination of these parameters. To 
determine the most important parameter in determining the reduction, we choose two cases, CaseEF and the CaseCentral, to illustrate. Fix five of the six parameters, we can calculate the impact of the uncertainty of the rest one parameter on the reduction. It can be seen that in both cases (the mass of pyrotechnic charge is the same), the dominating parameter is the emission factor $\left(e f_{E F}\right)$ of environmentally friendly charge, as the reduction changes largely $(>25 \%)$ when the uncertainty of $e f_{E F}$ varies from the upper bound to the lower bound while changes small (within 10\%) with other parameters (Table S3). The uncertainties due to using different "green" fireworks with higher emission factor have been discussed in the S4.5. The results are in the range of $15-65 \%$ with a central value $35 \%$. The $\sim 50 \%$ benefit we obtained based on CaseEF and CaseTRAD is the values close to the upper bounds, basing on the constraint by the observations. Though using the lowest emission factor of the "green" fireworks in CaseEF, the non-attainment still occurred. Our main conclusion (the total number of fireworks used at one time must be strictly restricted) should still valid for other "green" fireworks.

Table S3. Reductions of PM emissions in response to the change of one parameter while fixing the other five parameters as in CaseEF and CaseCentral.

\begin{tabular}{|c|c|c|c|c|c|c|}
\hline & \multicolumn{3}{|c|}{ CaseEF } & \multicolumn{3}{|c|}{ CaseCentral } \\
\hline & $\begin{array}{l}\text { lower } \\
\text { bound }\end{array}$ & $\begin{array}{l}\text { upper } \\
\text { bound }\end{array}$ & difference & $\begin{array}{l}\text { lower } \\
\text { bound }\end{array}$ & $\begin{array}{l}\text { upper } \\
\text { bound }\end{array}$ & difference \\
\hline$m_{u n \_1}$ & $54 \%$ & $50 \%$ & $4 \%$ & $37 \%$ & $34 \%$ & $3 \%$ \\
\hline$m_{p r_{-} 1}$ & $59 \%$ & $50 \%$ & $9 \%$ & $40 \%$ & $33 \%$ & $7 \%$ \\
\hline$m_{u n \_2}$ & $57 \%$ & $53 \%$ & $4 \%$ & $37 \%$ & $33 \%$ & $4 \%$ \\
\hline$m_{p y_{\_} 2}$ & $59 \%$ & $54 \%$ & $5 \%$ & $37 \%$ & $33 \%$ & $4 \%$ \\
\hline$e f_{T R A D}$ & $54 \%$ & $53 \%$ & $1 \%$ & $39 \%$ & $35 \%$ & $4 \%$ \\
\hline $\boldsymbol{e} \boldsymbol{f}_{E F}$ & $29 \%$ & $54 \%$ & $25 \%$ & $19 \%$ & $49 \%$ & $30 \%$ \\
\hline
\end{tabular}



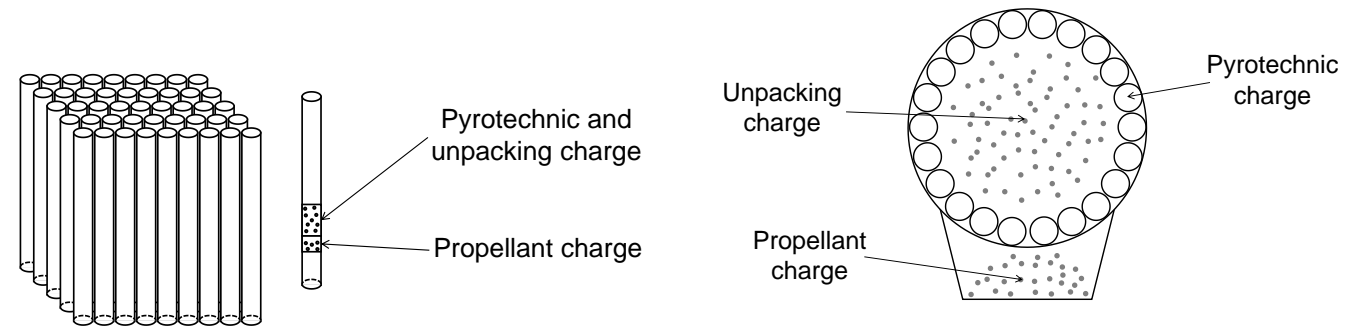

Figure S1. Typical structures of a type I firework (batteries and combinations, left) and a type II firework (aerial shell, right).

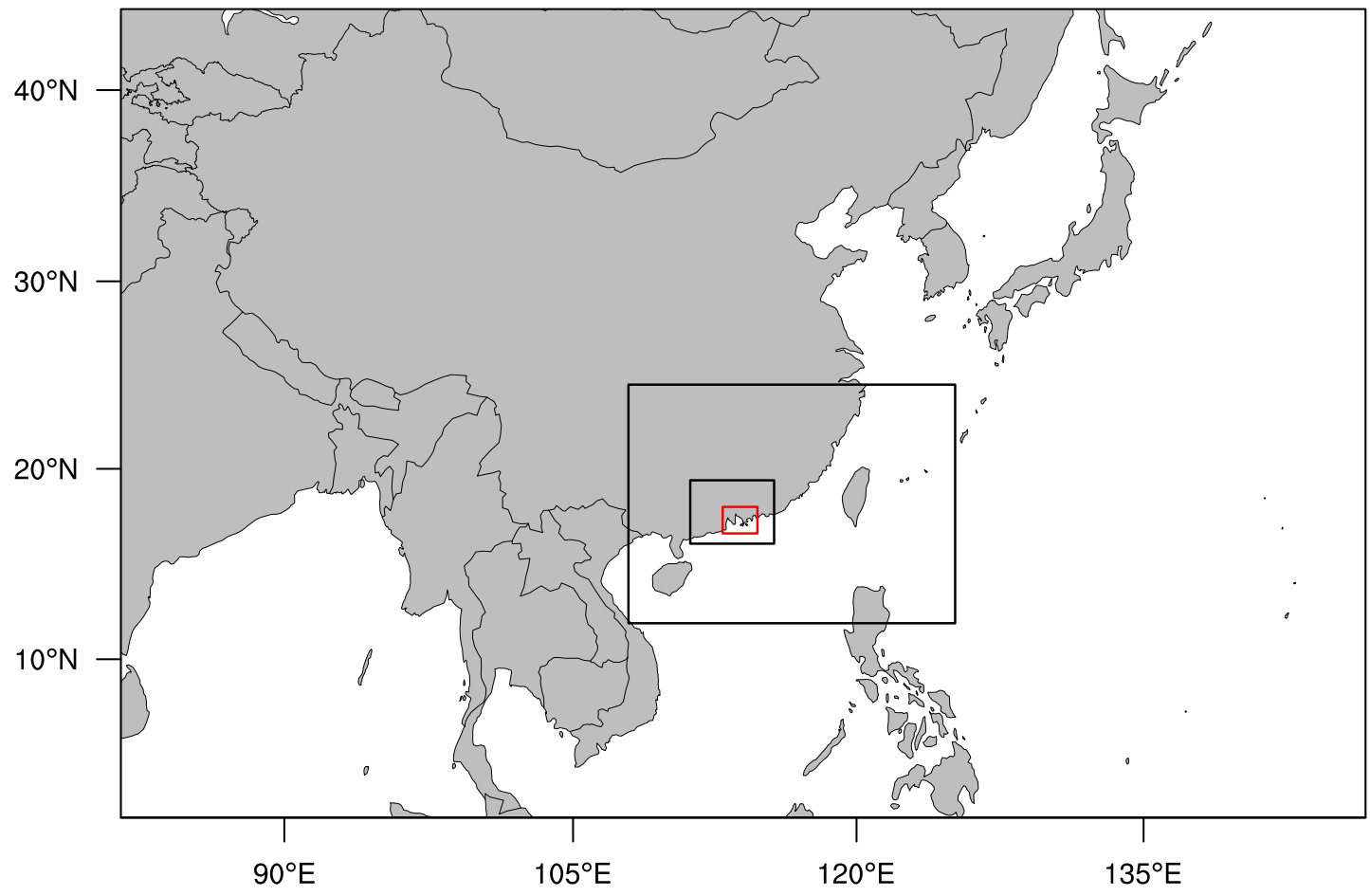

Figure S2. Nested domains used for WRF simulations with horizontal grid resolution $27 \mathrm{~km}, 9$

$\mathrm{km}, 3 \mathrm{~km}$, and 1 km denoted as D1, D2, D3 and D4, respectively. 


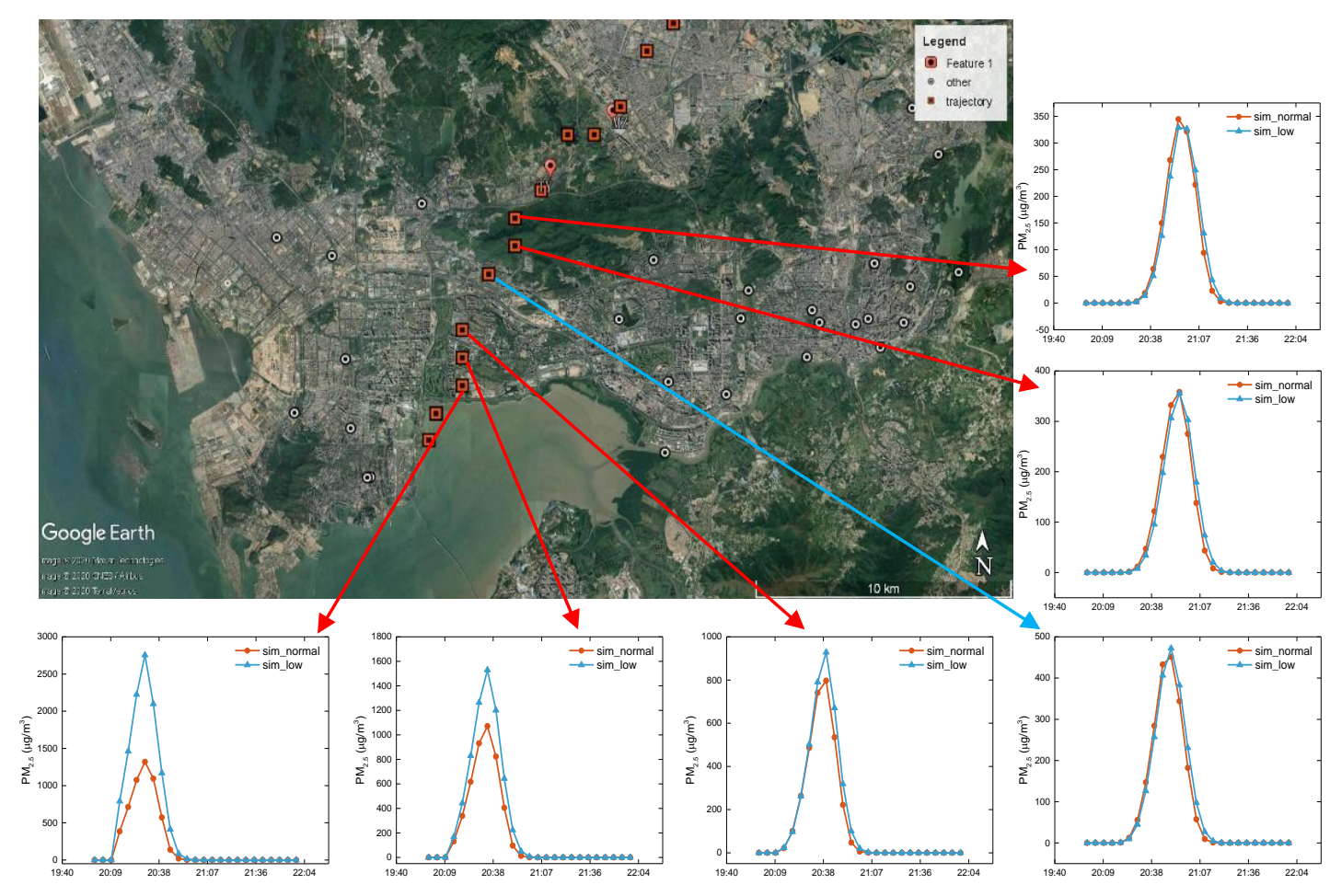

Figure S3. The time series of simulated $\mathrm{PM}_{2.5}$ along the trajectory in CaseEF of sim_normal and sim_low. The blue arrow shows the position where sim_low has the same peak value as sim_normal, indicating the impact of emission height vanishes at this position and beyond. This position is about $7 \mathrm{~km}$ away from the source. 


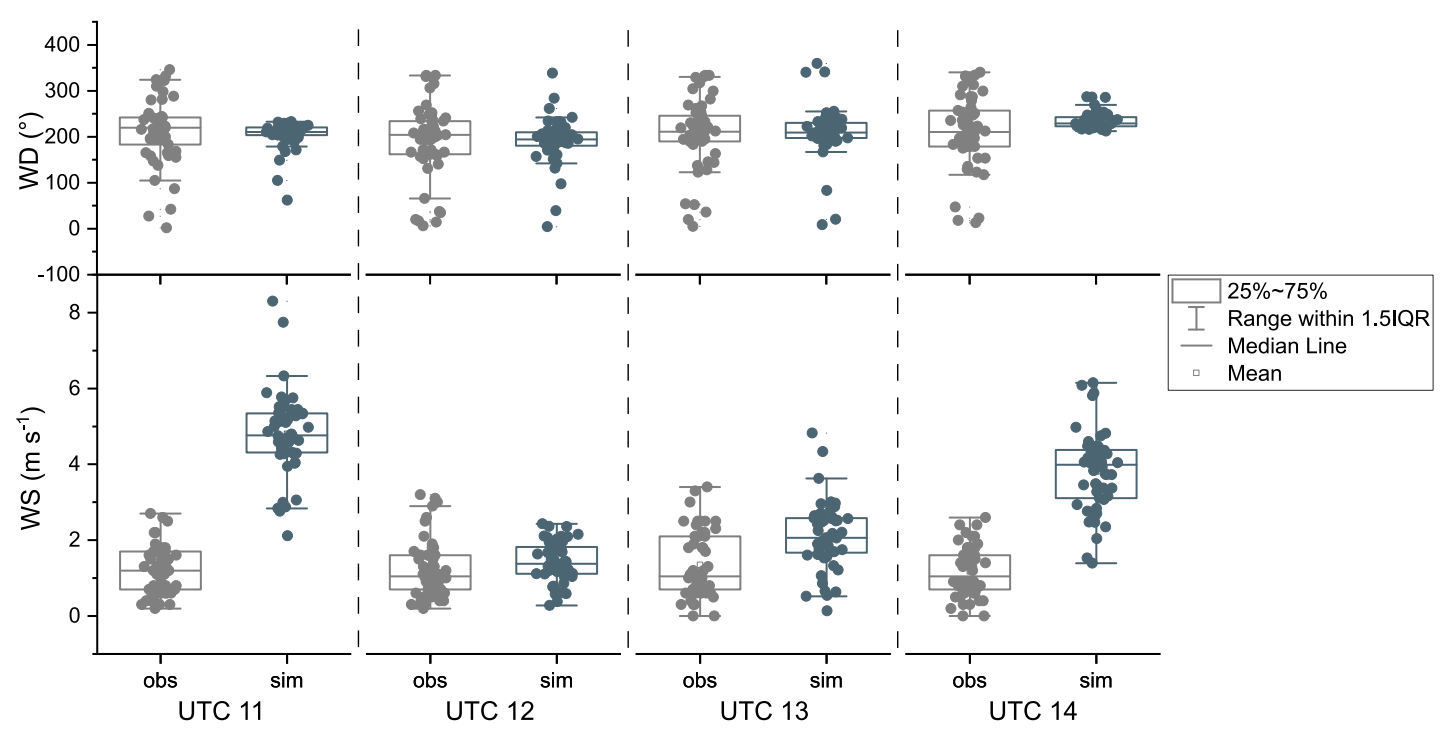

Figure S4. Box (with scatter) plot of wind direction (WD) and wind speed (WS) at 54 meteorological stations (see Figure S5) close to (within $\sim 5 \mathrm{~km}$ ) the plume trajectory before and after the fireworks display (starting at local time 20:00, i.e., UTC12).

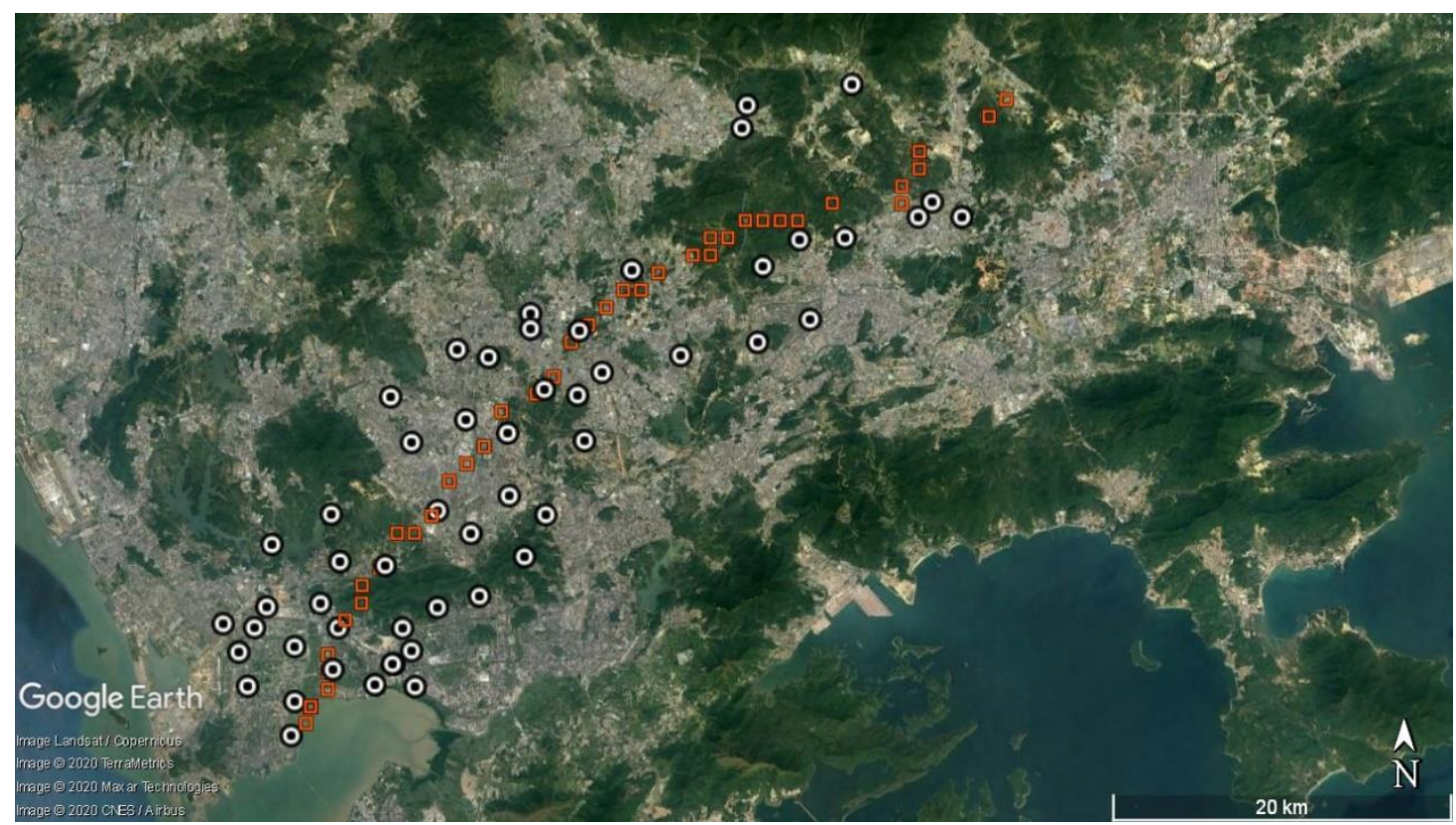

Figure S5. The 54 meteorological stations (black circles with white fill-in) related to Figure S4.

The red square is the trajectory of the plume. 
Table S4. PM and gases emissions distributed along heights.

\begin{tabular}{|c|c|c|c|c|c|c|c|c|c|c|c|c|}
\hline Layer & $\begin{array}{l}\mathrm{H} \\
\text { (m) }\end{array}$ & $\begin{array}{l}\text { PM } \\
(\mathrm{kg})\end{array}$ & $\begin{array}{c}\mathrm{S} \\
(\mathrm{kg})\end{array}$ & $\begin{array}{l}\mathrm{SO}_{2} \\
(\mathrm{~kg})\end{array}$ & $\begin{array}{l}\mathrm{PSO}_{4} \\
(\mathrm{~kg})\end{array}$ & $\begin{array}{l}\text { NO } \\
(\mathrm{kg})\end{array}$ & $\begin{array}{l}\mathrm{NO}_{2} \\
(\mathrm{~kg})\end{array}$ & $\begin{array}{c}\mathrm{PNO}_{3} \\
(\mathrm{~kg})\end{array}$ & $\begin{array}{c}\text { PMFINE } \\
\text { (kg) }\end{array}$ & $\begin{array}{l}\text { PMC } \\
(\mathrm{kg})\end{array}$ & $\begin{array}{c}\text { ALD2 } \\
(\mathrm{kg})\end{array}$ & $\begin{array}{c}\text { FORM } \\
(\mathbf{k g})\end{array}$ \\
\hline L1 & 18 & 881.96 & 6.17 & 6.17 & 9.25 & 0.035 & 0.009 & 5.26 & 426.47 & 440.98 & 0.94 & 0.35 \\
\hline $\mathbf{L 2}$ & 38 & 662.36 & 6.17 & 6.17 & 9.25 & 0.026 & 0.007 & 3.95 & 317.98 & 331.18 & 0.70 & 0.27 \\
\hline $\mathbf{L 3}$ & 59 & 662.36 & 6.17 & 6.17 & 9.25 & 0.026 & 0.007 & 3.95 & 317.98 & 331.18 & 0.70 & 0.27 \\
\hline L4 & 83 & 628.01 & 6.05 & 6.05 & 9.07 & 0.025 & 0.006 & 3.74 & 301.19 & 314.00 & 0.67 & 0.25 \\
\hline L5 & 108 & 794.25 & 7.65 & 7.65 & 11.48 & 0.032 & 0.008 & 4.73 & 380.91 & 397.12 & 0.84 & 0.32 \\
\hline L6 & 135 & 1126.72 & 10.85 & 10.85 & 16.28 & 0.045 & 0.011 & 6.72 & 540.37 & 563.36 & 1.19 & 0.45 \\
\hline L7 & 167 & 664.95 & 6.40 & 6.40 & 9.61 & 0.027 & 0.007 & 3.96 & 318.90 & 332.48 & 0.70 & 0.27 \\
\hline L8 & 206 & 831.19 & 8.01 & 8.01 & 12.01 & 0.033 & 0.008 & 4.95 & 398.63 & 415.59 & 0.88 & 0.33 \\
\hline L9 & 251 & 55.41 & 0.53 & 0.53 & 0.80 & 0.002 & 0.001 & 0.33 & 26.58 & 27.71 & 0.06 & 0.02 \\
\hline
\end{tabular}

Note. $\quad$ PMFINE $=P_{2.5}-P_{4} O_{4}-P N O_{3}=\frac{1}{2} P M-P_{4} O_{4}-P N O_{3} . \quad P M C=P M-P M_{2.5}-\frac{1}{2} P M$. ALD2 is acetaldehyde. FORM is formaldehyde.

Table S5. Parameters of linear regressions of the $\mathrm{PM}_{2.5}$ emission-response relationship for sim_normal, corresponding to Figure 3d.

\begin{tabular}{cccc}
\hline & slope & intercept & $\boldsymbol{r}^{\mathbf{2}}$ \\
\hline TY & 0.0854 & 4.6 & 1 \\
MZ & 0.0450 & 10.1 & 0.9996 \\
BT & 0.0440 & 2.7 & 1 \\
LH & 0.0385 & 1.1 & 1 \\
GH & 0.0246 & 0.8 & 1 \\
\hline
\end{tabular}




\section{References}

1. Dutcher, D. D.; Perry, K. D.; Cahill, T. A.; Copeland, S. A., Effects of indoor pyrotechnic displays on the air quality in the Houston Astrodome. Journal of the Air \& Waste Management Association 1999, 49, (2), 156-160.

2. Croteau, G.; Dills, R.; Beaudreau, M.; Davis, M., Emission factors and exposures from groundlevel pyrotechnics. Atmospheric Environment 2010, 44, (27), 3295-3303.

3. Byun, D. W.; Young, J.; Odman, M. T., Governing equations and computational structure of the community multiscale air quality (CMAQ) chemical transport model. In Science Algorithms of the EPA Models-3 Community Multiscale Air Quality (CMAQ) Modeling System, Byun, D. W.; Ching, J. K. S., Eds. US EPA: Washington, DC, 1999.

4. Byun, D. W.; Young, J.; Pleim, J.; Odman, M. T.; Alapaty, K., Numerical transport algorithms for the community multiscale air quality (CMAQ) chemical transport model in generalized coordinates. In Science Algorithms of the EPA Models-3 Community Multiscale Air Quality (CMAQ) Modeling System Byun, D. W.; Ching, J. K. S., Eds. US EPA: Washington, DC, 1999; Vol. 20460.

5. Pleim, J. E., A combined local and nonlocal closure model for the atmospheric boundary layer. Part I: Model description and testing. Journal of Applied Meteorology and Climatology 2007, 46, (9), 13831395.

6. Sutton, O. G., A theory of eddy diffusion in the atmosphere. Proceedings of the Royal Society of London Series a-Containing Papers of a Mathematical and Physical Character 1932, 135, (826), 143 165.

7. Byun, D. W.; Schere, K. L., Review of the governing equations, computational algorithms, and other components of the models-3 Community Multiscale Air Quality (CMAQ) modeling system. Applied Mechanics Reviews 2006, 59, (1-6), 51-77.

8. Emery, C.; Liu, Z.; Russell, A. G.; Odman, M. T.; Yarwood, G.; Kumar, N., Recommendations on statistics and benchmarks to assess photochemical model performance. Journal of the Air \& Waste Management Association 2017, 67, (5), 582-598.

9. Emery, C.; Tai, E.; Yarwood, G., Enhanced meteorological modeling and performance evaluation for two Texas ozone episodes. Prepared for the Texas natural resource conservation commission, by ENVIRON International Corporation 2001. 
10. Carvalho, D.; Rocha, A.; Gomez-Gesteira, M.; Santos, C. S., WRF wind simulation and wind energy production estimates forced by different reanalyses: Comparison with observed data for Portugal. Applied Energy 2014, 117, 116-126.

11. American Fireworks Standards Laboratory (AFSL), Standards for consumer fireworks. In Opti: 2019.

12. Sun, R. B. Formula for colorful fireworks. CN Patent CN103497077A, Jan 08, 2013.

13. Yuan, C. Study on Charge Technology of Smokeless Aerial Shell (in Chinese). Master, Nanjing University of Science and Technology, 2012.

14. Pan, Z. M.; Lin, X. Y.; Li, S. Y. Large festive firework with micro-pore firework ammunition as depucelation ammunition and preparation method of large festive firework. CN Patent CN102192685A, Sep 21, 2011.

15. Lin, X. Y.; Pan, Z. M.; Li, S. Y. Modular smokeless firework emission ammunition with multihierarchy hole structure and preparation method for modular smokeless firework emission ammunition. CN Patent CN102584506A, Jul 18, 2011.

16. Lin, X. Y.; Liu, Y. J.; Shi, S.; Pan, R. M., Charging Technology of Micropores Smokeless Propellant for Firework (in Chinese). Journal of Nanjing University of Science and Technology 2011, 35, (04), $552-$ 557.

17. Tang, G. L.; Zhao, J. Y.; Wu, H.; Du, Z. M., Study on the Improvement of Black Powder. Initiators \& Pyrotechnics 2002, (04), 25-26+33.

18. Kong, X. L.; Song, J. F., Preliminary Study on the Selection of Smokeless Fireworks Charges (1) On the selection of smokeless oxidants (in Chinese). Fireworks Technology and Market 2009, (04), 16.

19. Liuyang Jixiang Environmental Firework Material Development Co., L., Smokeless and sulfur-free propellant "Jixiang One" (in Chinese). Fireworks Technology and Market 2017, pp 14-16.

20. Zhou, Z. H. A Study on Ignition and Propagationof Aerial Shell Charge with Little Burning Smoke (in Chinese). Master, Nanjing University of Science and Technology, 2012.

21. Han, Z. Y.; Jiang, Q.; Du, Z. M.; Hoon, H. H.; Yu, Y.; Zhang, Y. P.; Gong, L.; Sun, Y., A novel environmental-friendly and safe unpacking powder without magnesium, aluminum and sulphur for fireworks. Journal of Hazardous Materials 2019, 373, 835-843.

22. Camilleri, R.; Vella, A. J., Emission Factors for Aerial Pyrotechnics and Use in Assessing Environmental Impact of Firework Displays: Case Study from Malta. Propellants Explosives S18 
Pyrotechnics 2016, 41, (2), 273-280. 